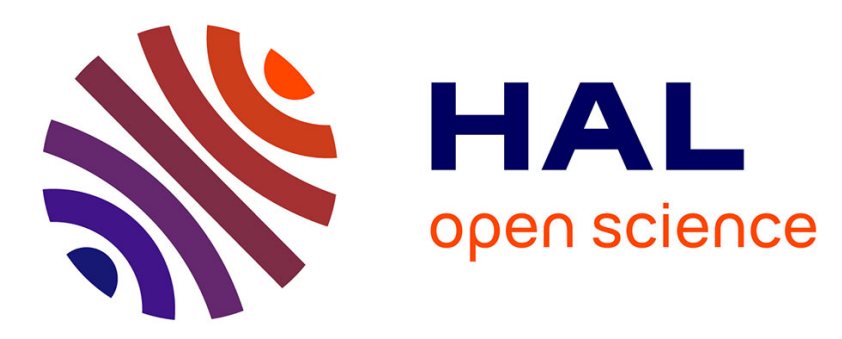

\title{
Chiral-selective growth of single-walled carbon nanotubes on Fe-based catalysts using $\mathrm{CO}$ as carbon source
}

Maoshuai He, Pavel V. Fedotov, Alexander Chernov, Elena D. Obraztsova, Hua Jiang, Na Wei, Hongzhi Cui, Jani Sainio, Weiguo Zhang, Hua Jin, et al.

\section{To cite this version:}

Maoshuai He, Pavel V. Fedotov, Alexander Chernov, Elena D. Obraztsova, Hua Jiang, et al.. Chiralselective growth of single-walled carbon nanotubes on Fe-based catalysts using CO as carbon source. Carbon, 2016, 108, pp.521 - 528. 10.1016/j.carbon.2016.07.048 . hal-01714535

\section{HAL Id: hal-01714535 \\ https://hal.science/hal-01714535}

Submitted on 7 Jul 2021

HAL is a multi-disciplinary open access archive for the deposit and dissemination of scientific research documents, whether they are published or not. The documents may come from teaching and research institutions in France or abroad, or from public or private research centers.
L'archive ouverte pluridisciplinaire HAL, est destinée au dépôt et à la diffusion de documents scientifiques de niveau recherche, publiés ou non, émanant des établissements d'enseignement et de recherche français ou étrangers, des laboratoires publics ou privés. 


\title{
Chiral-selective growth of single-walled carbon nanotubes on Fe-based catalysts using $\mathrm{CO}$ as carbon source
}

\author{
Maoshuai He ${ }^{\mathrm{a}, \mathrm{b},{ }^{*}}$, Pavel V. Fedotov ${ }^{\mathrm{c}}$, Alexander Chernov ${ }^{\mathrm{c}}$, Elena D. Obraztsova ${ }^{\mathrm{c}}$,

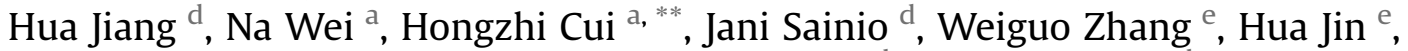 \\ Maarit Karppinen ${ }^{\mathrm{e}}$, Esko I. Kauppinen ${ }^{\mathrm{d}}$, Annick Loiseau ${ }^{\mathrm{b}}$ \\ a School of Materials Science and Engineering, Shandong University of Science and Technology, 266590 Qingdao, People's Republic of China ${ }^{\text {b }}$ \\ Laboratoire d'Etude des Microstructures, ONERA-CNRS, BP 72, 92322 Chatillon Cedex, France \\ ${ }^{c}$ A.M. Prokhorov General Physics Institute RAS, 38 Vavilov Street, 119991 Moscow, Russia \\ ${ }^{\mathrm{d}}$ Department of Applied Physics, Aalto University School of Science, P.O. Box 15100, FI-00076 Aalto, Finland \\ e Department of Chemistry, Aalto University School of Chemical Technology, P.O. Box 16100, FI-00076 Aalto, Finland
}

\begin{abstract}
MgO supported monometallic Fe (Fe-MgO) and bimetallic FeMn (FeMn-MgO) catalysts were developed for growing carbon nanotubes using $\mathrm{CO}$ as carbon source. Characterizations on the $\mathrm{Fe}-\mathrm{MgO}$ catalyst revealed that Fe cations were well-dispersed in the porous $\mathrm{MgO}$ support, forming a solid solution. Since most Fe cations in the solid solution are difficult to reduce, $\mathrm{Fe}-\mathrm{MgO}$ can only catalyze the growth of single-walled carbon nanotubes (SWCNTs) at temperatures of $700{ }^{\circ} \mathrm{C}$ and above. While Fe cations in FeMn-MgO could be reduced at lower temperatures with the assistance of $\mathrm{Mn}$, catalyzing the subsequent growth of SWCNTs. Compared with most SWCNTs grown on components like Co or Ni at ambient reaction pressure, the Fe-catalyzed SWCNTs demonstrate rather narrow chirality distributions. Particularly, preferential $(6,5)$ tube growth on FeMn-MgO was achieved at $600^{\circ} \mathrm{C}$. The narrow SWCNT chirality distribution could be inherently related to the high carbon solubility of Fe nanoparticles, favoring the nucleation of SWCNTs by a perpendicular mode. The present studies not only offer essential insights into SWCNT growth mechanisms, but can guide the design of novel catalysts for chirality-controlled growth of SWCNTs.
\end{abstract}

\section{Introduction}

Controlled synthesis of carbon nanotubes has been challenging but highly preferred for the applications of carbon nanotubes in a wide range of fields, especially in nanoelectronics and photonics [1]. Due to the good controllability, low cost and easy scale-up, chemical vapor deposition (CVD) technique has shown great potential in controlled growth of carbon nanotubes, such as wallnumber control [2-4], diameter control [5,6], density control [7] as well as chirality control [8-12]. Among them, chiralitycontrolled growth is one of the most challenging tasks in single-

\footnotetext{
* Corresponding author. School of Materials Science and Engineering, Shandong University of Science and Technology, 266590 Qingdao, People's Republic of China. ** Corresponding author.

E-mail addresses: maoshuai.he@sdust.edu.cn (M. He), cuihongzhi1965@163.com (H. Cui).
}

walled carbon nanotube (SWCNT) synthesis field. In CVD processes, catalyst plays a crucial role both in nucleating carbon nanotubes and in determining the chiralities of SWCNTs [13]. Fiawoo et al. [14] discriminated two tube nucleation modes: perpendicular one and tangential one, corresponding to different tubeparticle junction. Further work by Diarra et al. [15] suggests that the wetting properties and carbon solubility of catalytic nanoparticles could be linked with the tube nucleation mode. So far, correlation between nucleation mode and SWCNT chirality distribution has not yet established. However, some recent studies indicate that SWCNTs bias specific chiralities or chiral angles are grown by either tangential [12] or perpendicular modes [6].

There is a growing list of supported catalysts implemented for chiral-selective growth of SWCNTs, e.g. CoMo- $\mathrm{SiO}_{2}[8,16-18]$, $\mathrm{FeRu}-\mathrm{SiO}_{2}$ [9], $\mathrm{Co}-\mathrm{SiO}_{2}$ [19], CoMn-MCM-41 [20], Ni-SiO 2 [21], $\mathrm{FeCu}-\mathrm{MgO}$ [10], $\mathrm{Co}-\mathrm{MgO}$ [11,22], and $\mathrm{CoCu}-\mathrm{SiO}_{2}$ [23], just to name a few. Recently, progresses have been made in producing SWCNTs 
with metallic chirality $[12,24]$ or even near-zigzag chirality $[24,25]$. Despite of the progresses, Fe-based catalyst $[9,10]$ and MgO support $[10,11,22]$ are highly preferred not only because of their low cost and easy removal after growth, but also because Fe-catalyzed SWCNTs usually possess a narrow chirality distribution even when growing at ambient pressure. A number of Fe-based catalysts $[9,10,26-28]$ have been developed for growing carbon nanotubes so far. Unfortunately, not many of them are applicable for chiralselective growth of SWCNTs. The previous failure in narrowing the chirality distribution of SWCNTs mainly arises from the relative high reduction temperature of iron oxide $[10,27]$. As the high reduction temperature could induce the coalescence of nanoparticles, causing the growth of SWCNTs with a wide chirality/ diameter distribution. Therefore, developing novel Fe-based catalyst for low-temperature synthesis of SWCNTs is essential for both fundamental understandings to their growth mechanisms and chiral-selective growth of SWCNTs.

In this study, we will first report an MgO-supported monometallic Fe catalyst for growing SWCNTs using CO as the carbon source. The chirality distributions of SWCNTs grown on the $\mathrm{Fe}-\mathrm{MgO}$ catalyst will be presented and discussed. Meanwhile, the Fe particle nucleation and carbon nanotube growth mechanisms will be clarified based on characterizations of the catalyst before and after CVD reaction. In addition, a FeMn-MgO catalyst will be designed for low-temperature growth of SWCNTs, the chirality selectivity of which will be evaluated by optical characterization techniques. Finally, the respective roles of Mn and Fe during SWCNT growth will be discussed.

\section{Materials and methods}

\subsection{Preparation of $\mathrm{Fe}-\mathrm{MgO}$ catalyst}

The $\mathrm{Fe}-\mathrm{MgO}$ catalyst was prepared by atomic layer deposition (ALD) technique [10]. The precursors for Fe and $\mathrm{MgO}$ are iron (III) acetylacetonate (Aldrich, 97\%) and magnesium carbonate hydroxide hydrate (Aldrich, 99\%), respectively. Porous MgO was prepared by annealing magnesium carbonate hydroxide hydrate in open air and loaded into an F120 ALD system. After preheating MgO in nitrogen at $400{ }^{\circ} \mathrm{C}$ for $5 \mathrm{~h}$, iron (III) acetylacetonate was heated to $165{ }^{\circ} \mathrm{C}$ and carried by nitrogen to pass through the MgO support. The Fe-deposition period lasted for $6 \mathrm{~h}$. After flushing by nitrogen, the deposited catalyst was further annealed at $450{ }^{\circ} \mathrm{C}$ with synthetic air for $4 \mathrm{~h}$ to remove the residual organic ligands. All the process was kept at a reduced pressure of $6-10 \mathrm{kPa}$.

\subsection{Preparation of FeMn-MgO catalyst}

Manganese (II) acetate tetrahydrate (Aldrich, 99\%) with a mass of $0.74 \mathrm{~g}$ was first dissolved in $100 \mathrm{~mL} \mathrm{H}_{2} \mathrm{O}$ and mixed with $4.0 \mathrm{~g}$ $\mathrm{MgO}$. After drying overnight, the mixture was annealed in air at $450{ }^{\circ} \mathrm{C}$ for $2 \mathrm{~h}$. The obtained $\mathrm{Mn}-\mathrm{MgO}$ powder was subsequently added into an aqueous solution of iron (III) nitrate nonahydrate ( $2.3 \mathrm{~g}$ in $100 \mathrm{ml} \mathrm{H} \mathrm{H}_{2}$ ). The catalyst was annealed at $450{ }^{\circ} \mathrm{C}$ in air for another $4 \mathrm{~h}$ after drying and finally ground into fine powder for further use.

\subsection{Growth of carbon nanotubes by CVD}

CVD growth of carbon nanotubes was performed on a homemade horizontal reactor with a quartz tube (inner diameter: $40 \mathrm{~mm}$ ) [29]. Catalyst was loaded into the middle of the quartz tube and heated to desired temperature in the presence of $200 \mathrm{~cm}^{3} / \mathrm{min}$ helium. After being stabilized at the desired temperatures $\left(600^{\circ} \mathrm{C}\right.$, $700{ }^{\circ} \mathrm{C}$ and $800{ }^{\circ} \mathrm{C}$ ), $\mathrm{CO}$ with a flow rate of $200 \mathrm{~cm}^{3} / \mathrm{min}$ was introduced to the CVD reactor to replace helium. The CO feeding process lasted for $15 \mathrm{~min}$ and the system was cooled down to room temperature in the protection of helium.

\subsection{Catalyst and carbon nanotube characterizations}

X-ray diffraction (XRD) patterns were recorded using a Panalytical diffractometer with $\mathrm{Cu} \mathrm{K} \alpha$ radiation $(\lambda=1.5406 \AA)$. X-ray photoelectron spectroscopy (XPS) measurements were carried out with a Surface Science Instruments SSX-100 ESCA spectrometer using monochromated $\mathrm{Al} \mathrm{K} \alpha$ radiation $(\mathrm{h} \nu=1486.6 \mathrm{eV}) . \mathrm{H}_{2}$ temperature-programmed reduction (TPR) was performed on a Quantachrome Instruments CHEMBET-3000. Approximately $100 \mathrm{mg}$ of FeMn-MgO powder was first loaded into a quartz cell, a mixture of $\mathrm{H}_{2}$ and $\mathrm{N}_{2}$ (1:9) was subsequently introduced to the system and the catalyst was heated from room temperature to $800^{\circ} \mathrm{C}$, at a rate of $10^{\circ} \mathrm{C} / \mathrm{min}$. The $\mathrm{H}_{2}$ consumed during the TPR was monitored by a thermal conductivity detector (TCD).

The morphology and structure of both catalyst and carbon nanotubes were characterized by a JEOL-2200FS FEG TEM/STEM operated at $80 \mathrm{kV}$ and $200 \mathrm{kV}$. Raman spectra of as-produced carbon nanotubes were collected using a Horiba Jobin-Yvon Labram300 Raman spectrometer. $633 \mathrm{~nm}$ and $514 \mathrm{~nm}$ lasers were used as the excitation sources for Raman measurements. To remove $\mathrm{MgO}$ support and catalyst after carbon nanotube growth, diluted $\mathrm{HCl}$ ( $3 \mathrm{M}$ ) was added to the products. The purified carbon nanotubes were then washed with $\mathrm{H}_{2} \mathrm{O}$ and dispersed in an aqueous solution of sodium cholate (2 wt\%). After centrifugation, the tube dispersions were finally subjected to photoluminescence characterizations using a Horiba Jobin-Yvon NanoLog-4 spectro-fluorometer.

\section{Results and discussion}

\subsection{Growth of carbon nanotubes on $\mathrm{Fe}-\mathrm{MgO}$ catalyst}

Fig. 1a depicts a typical TEM image of the Fe-MgO catalyst. Hardly any isolated Fe nanoparticle was observed on the surface of the MgO support. However, energy-dispersive X-ray spectroscopy (EDX) analysis and XPS characterization clearly demonstrate the presence of Fe in the catalyst (ESI Fig. S1). The composition of the catalyst was further analyzed by EDX mapping (Fig. 1b-d), showing that the elements of $\mathrm{Fe}, \mathrm{O}$ and $\mathrm{Mg}$ are almost overlapped and the $\mathrm{Fe}$ element disperses uniformly in the $\mathrm{MgO}$ support. The characterization results indicate that Fe cations are dissolved into the $\mathrm{MgO}$ matrix forming a Fe- $\mathrm{MgO}$ solid solution. Indeed, the formation of a solid solution is further confirmed by the XRD pattern of the catalyst, where only lines of MgO structures could be resolved [10]. The above results indicate that a considerable diffusion of $\mathrm{Fe}$ into the $\mathrm{MgO}$ matrix occurs during catalyst preparation, promoting the high extent of bulk $\mathrm{Fe}-\mathrm{MgO}$ solid solution. It is noted that although the catalyst calcination temperature is not high, considering the high activity of metal atoms deposited onto the $\mathrm{MgO}$ support and the vacuum applied during ALD processes, the formation of a $\mathrm{Fe}-\mathrm{MgO}$ solid solution is reasonable.

Growth of carbon nanotubes on the $\mathrm{Fe}-\mathrm{MgO}$ catalyst was performed at temperatures of $600{ }^{\circ} \mathrm{C}$ and above. As we reported previously [10], only multi-walled carbon nanotubes (MWCNTs) were synthesized at $600^{\circ} \mathrm{C}$. The formation of large-diameter MWCNTs is attributed to the presence of a trace amount of large-size iron oxide particles, which are located at the "unreactive" sites of MgO support and readily reduced at a low temperature for the synthesis of MWCNTs. The result of present study is very similar to previous findings $[26,28]$ that no SWCNT growth was observed on Fe-MgO catalysts at temperatures below $700{ }^{\circ} \mathrm{C}$.

With the increase of reaction temperature, SWCNTs were 

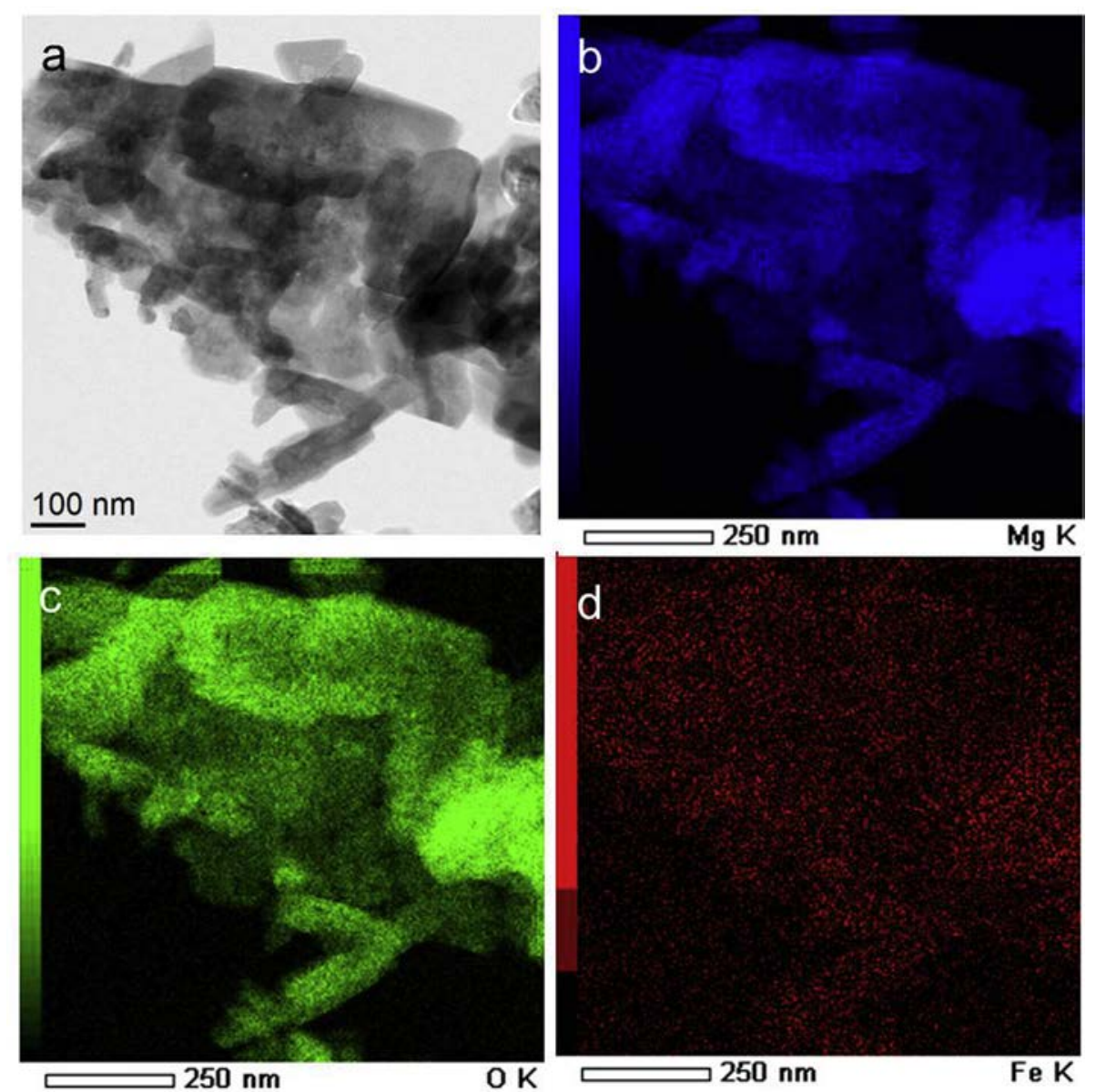

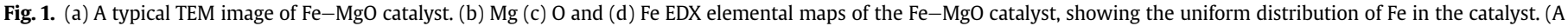
colour version of this figure can be viewed online.)

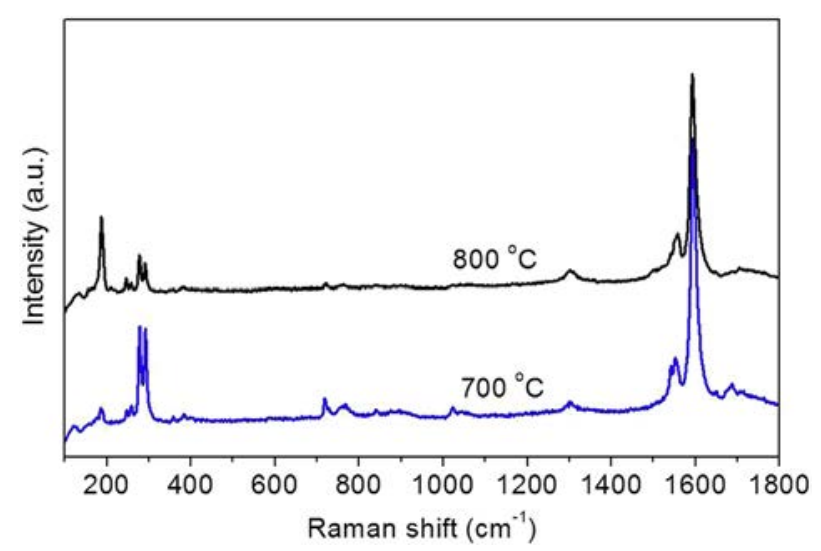

Fig. 2. Raman spectra of carbon nanotubes grown on $\mathrm{Fe}-\mathrm{MgO}$ catalyst using $\mathrm{CO}$ as the carbon source at $700{ }^{\circ} \mathrm{C}$ and $800{ }^{\circ} \mathrm{C}$, respectively. The excitation wavelength of the laser is $633 \mathrm{~nm}$. (A colour version of this figure can be viewed online.)

observed to grow on the $\mathrm{Fe}-\mathrm{MgO}$ catalyst. Fig. 2 demonstrates the Raman spectra of the products grown at $700{ }^{\circ} \mathrm{C}$ and $800^{\circ} \mathrm{C}$. Besides the high intensity ratio between $G$ mode and $D$ mode, radial breathing modes (RBMs) were observed in the Raman spectra of the tubes, indicative of the presence of high-quality SWCNTs. It is noteworthy to mention that Li et al. [28] and Ago et al. [26] also reported the growth of high-quality SWCNTs on Fe-MgO catalysts.
However, in both of their experiments, methane was used as the carbon source and the produced SWCNTs have broad diameter distributions. As demonstrated by the photoluminescence spectrum of methane-grown SWCNTs on $0.6 \mathrm{wt} \% \mathrm{Fe}-\mathrm{MgO}[26],(7,5)$ and $(7,6)$ tubes have the highest photoluminescence intensity. Besides, other species, like $(6,5),(8,4),(8,6),(8,7),(9,4)$ and $(9,5)$ also exhibit relatively high emission intensities, denoting these tube species also occupy substantial proportion in the product. The possible reasons for the broad chirality distribution of methanegrown SWCNTs are attributed to selective nucleation and destroy of small-diameter SWCNT caps by hydrogen generated by methane decomposition $[16,30]$.

Different from methane, $\mathrm{CO}$ has been reported to facilitate the growth of SWCNTs with a narrow chirality distribution at low growth temperatures [16,30]. Our preliminary studies further suggest that $\mathrm{CO}$ could increase the carburization degree of nanoparticles, leading to the dissolution of carbon in nanoparticles with higher carbon fractions. More detailed discussion on carburization of nanoparticles is beyond the scope of this paper. As suggested by the high-frequency RBMs in the Raman spectrum of SWCNTs grown at $700{ }^{\circ} \mathrm{C}$ (Fig. 2), most of the produced SWCNTs have diameters smaller than $1.0 \mathrm{~nm}$. The production of small-diameter SWCNTs is also confirmed by TEM characterizations (ESI Fig. S2). In addition, intermediate frequency modes (IFMs, 700-1200 $\mathrm{cm}^{-1}$ ), which are correlated with small-diameter SWCNTs, were also observed in the Raman spectrum. With the increase of growth temperature, RBMs with low-frequency numbers became 
significant while the relative intensity of IFMs in the Raman spectrum decreased considerably (Fig. 2). The observations suggest the formation of more large-diameter tubes at $800{ }^{\circ} \mathrm{C}$. In order to evaluate the chirality distributions of SWCNTs grown on $\mathrm{Fe}-\mathrm{MgO}$ catalyst, photoluminescence characterizations were carried out on the dispersions of SWCNTs. The photoluminescence emission intensities recorded with three specific resonant excitation wavelengths are displayed in Fig. $3 a$ and $b$. In the photoluminescence of $700{ }^{\circ} \mathrm{C}$-grown SWCNTs, there are three intense emissions (centered at $980 \mathrm{~nm}, 963 \mathrm{~nm}$ and $1032 \mathrm{~nm}$ ) (Fig. 3a), arising from the emissions of $(6,5)$ tubes, $(8,3)$ tubes and $(7,5)$ tubes, respectively. The results indicate that such three tube species are the dominant components in the $700{ }^{\circ} \mathrm{C}$-grown products. The claim is further confirmed by the photoluminescence excitation/emission map for the SWCNT dispersion (Fig. 3c). Clearly, except $(6,5),(8,3)$ and $(7,5)$ species, the emission intensity of other SWCNT species are relatively low, suggesting that SWCNTs grown at $700^{\circ} \mathrm{C}$ on the $\mathrm{Fe}-\mathrm{MgO}$ catalyst have a narrow chirality distribution. In addition, the chirality distribution of SWCNTs broadens with the increase of the reaction temperature (Fig. $3 \mathrm{~b}$ and $\mathrm{d}$ ), which is consistent with many previous studies [8-10,16,19,21].

Besides the intimate dependencies on parameters related to CVD growth process, such as pressure, temperature and carbon source, the chirality distribution of SWCNTs also relies heavily on the compositions of the catalyst nanoparticles [31,32]. For example, Chiang et al. [31] reported the tuning of SWCNT chirality by adjusting the composition of $\mathrm{Ni}_{\mathrm{x}} \mathrm{Fe}_{1-\mathrm{x}}$ nanoparticles. When incorporating Fe into the lattices of Ni nanoparticles, the chirality distribution of SWCNTs grown on the alloy nanoparticles became narrower. Similarly, the compositional effects on the chirality distributions of SWCNTs were also verified in our previous studies $[19,21]$. It is noted that SWCNTs grown on either Co $[18,19]$ or $\mathrm{Ni}$ [21] at ambient pressure usually demonstrate relatively broad chirality distributions. Although growth of SWCNTs with a very narrow chirality distribution was also reported on Co-based catalyst $[16,18]$, such a high-chiral-selectivity growth was mainly achieved at high reaction pressures. In contrast, on the $\mathrm{Fe}-\mathrm{MgO}$ catalyst, SWCNTs synthesized at ambient pressure show a relatively narrow chirality distribution (Fig. 3c).

Why Fe particles catalyze SWCNTs with a much narrower chirality distribution than those grown on $\mathrm{Ni}$ or $\mathrm{Co}$ at similar growth conditions is still an open question. Previous work attempted to interpret the results using epitaxial growth [33] where the catalyst nanoparticle serves as the template for SWCNT nucleation, determining the chirality of SWCNT grown on it. While we suggest here that one should interpret the results with the tube nucleation mode, i.e. perpendicular or tangential mode, which depends on the carbon contents of metal nanoparticles [14]. As Fe particles have higher carbon solubility [34] than $\mathrm{Ni}$ or Co particles with same sizes, SWCNTs nucleate on Fe nanoparticles tend to adopt a more perpendicular mode with the SWCNT diameter much smaller than the size of nanoparticle. Therefore, SWCNTs
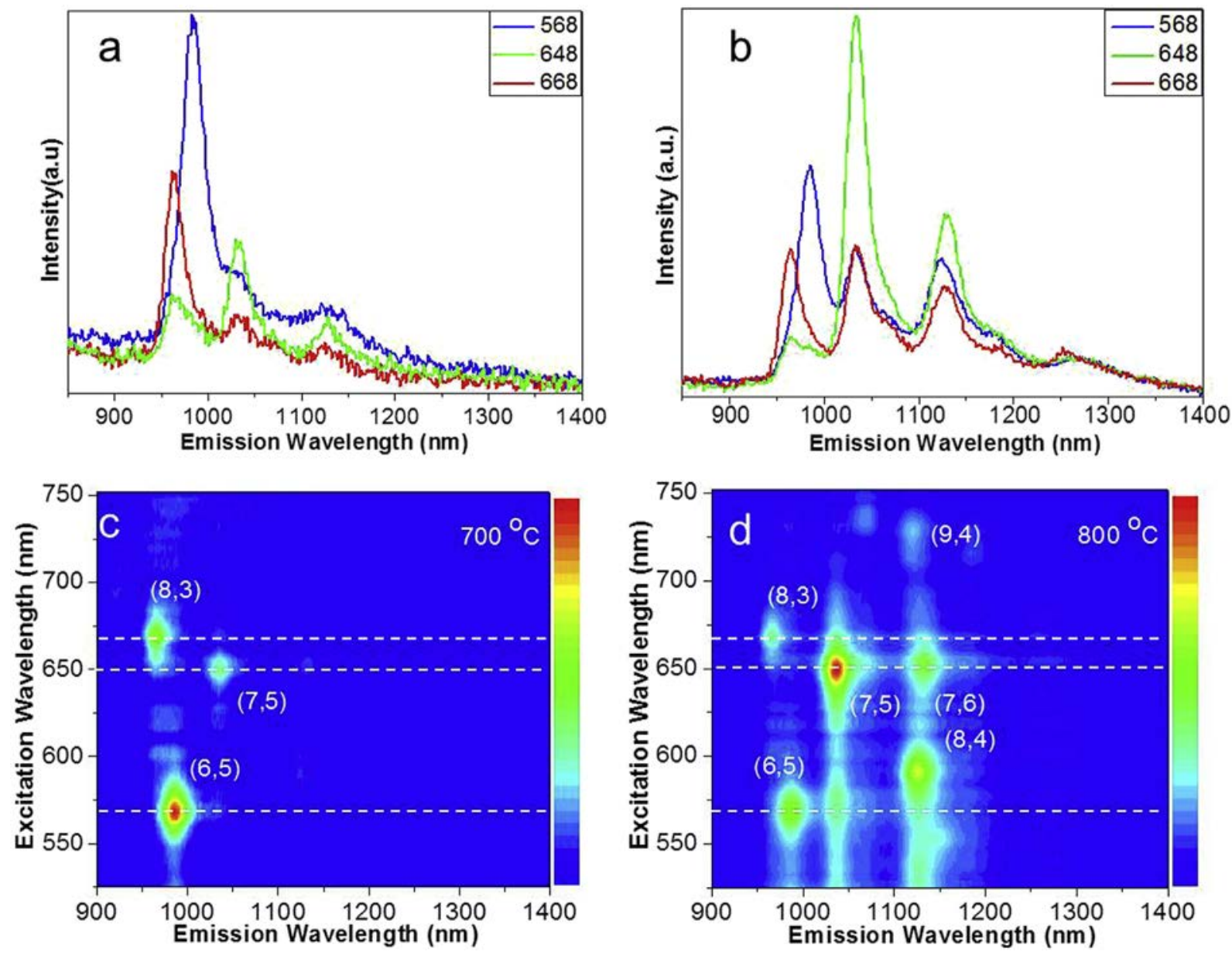

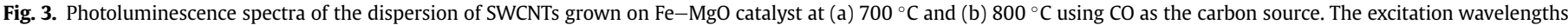

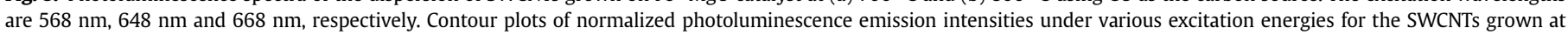
$700{ }^{\circ} \mathrm{C}$ (c) and $800{ }^{\circ} \mathrm{C}(\mathrm{d})$. (A colour version of this figure can be viewed online.) 
grown on Fe nanoparticles display a tendency to have very small diameters. Besides, $(6,5)$ tubes, possessing a small diameter and more stable configuration than other species [35], are more favored to form. Consequently, predominant $(6,5)$ SWCNT synthesis can be achieved on Fe-based catalysts $[9,10,36]$ even at ambient pressure. In contrast, due to the relatively low carbon solubility in Co particles, SWCNTs nucleated on them do not have very small diameters and narrow chirality distributions. It is noted that increasing the reaction pressure increases the chemical potential of carbon in the atmosphere. As a result, the carbon fraction in metal nanoparticles (like $\mathrm{Co}$ ) could be increased at high reaction pressures, favoring the growth of SWCNTs with a perpendicular mode. Such a perpendicular mode growth thus also accounts for the high-chiral-selectivity synthesis SWCNTs on Co catalysts when applying high pressures during CVD [16,18].

Despite the fact that hardly any Fe nanoparticles exist on the surface of the $\mathrm{Fe}-\mathrm{MgO}$ catalyst, Fe cations in the $\mathrm{MgO}$ matrix migrate onto the surface of $\mathrm{MgO}$ support upon reduction by $\mathrm{CO}$ at the reaction temperatures. Under such a mild reduction temperature $\left(700^{\circ} \mathrm{C}\right)$, mainly near-surface $\mathrm{Fe}$ cations are reduced, forming small-size Fe nanoparticles. The migration of Fe to the surface is verified by the XPS measurement results, which demonstrate that the atomic concentration of Fe in the catalyst surface increases from $0.6 \%$ before the CVD to $1.3 \%$ after the reaction. Furthermore, the sizes of reduced Fe particles could be very small as XRD characterizations on the products (ESI Fig. S3) did not show any new phase compared with the raw catalyst [10]. With the increase of the reaction temperature $\left(800{ }^{\circ} \mathrm{C}\right.$, for example), more Fe cations are reduced to form Fe particles with a broad size distribution, causing the growth of SWCNTs with different chiralities. Consequently, the achieved SWCNTs have a wide chirality distribution. At high reaction temperatures, MWCNTs were hardly grown on the catalyst. There are two reasons could account for the lack of MWCNTs in the products synthesized at high temperatures. On the one hand, the large Fe particles which is active at a low reaction temperature is not activated at the reaction environments; On the other hand, the carbon soluble in large Fe particles increases with increasing temperatures, favoring the growth of small diameter SWCNTs by a tangential mode $[14,15]$. The schematic illustration of Fe reduction and carbon nanotube synthesis on $\mathrm{Fe}-\mathrm{MgO}$ catalyst at different temperatures is presented in Fig. 4.

\subsection{Growth of carbon nanotubes on FeMn-MgO catalyst}

It has been empirically observed that SWCNT chirality distribution becomes narrower with the decrease of reaction temperature $[9,10,16]$. In order to decrease the reduction temperature of active component in the catalyst, a second metal is usually added in some catalyst systems, like the respective use of $\mathrm{Ru}$ and $\mathrm{Cu}$ in $\mathrm{FeRu}-\mathrm{SiO}_{2}$ [9] and $\mathrm{FeCu}-\mathrm{MgO}[10,36]$ catalyst systems where synergistic effects occur during SWCNT CVD growth. Indeed, such kind of synergism has been widely explored in a number of catalysts that have been applied in Fischer-Tropsch synthesis [37,38] where $\mathrm{CO}$ is used as one of the starting materials. Among them, FeMn catalysts have shown promise in enhancing the reduction of Fe and the selectivity for light olefins remarkably [39,40]. However, to date, the application of FeMn catalyst in SWCNT growth has rarely been reported.

Fig. 5a displays the RBM region in the Raman spectra of SWCNTs grown on the FeMn-MgO catalyst at $600{ }^{\circ} \mathrm{C}$ with two different excitation wavelengths. Obviously, mainly RBM peaks with frequencies higher than $250 \mathrm{~cm}^{-1}$ were detected. The photoluminescence excitation/emission map for the SWCNT dispersion clearly shows that predominant $(6,5)$ tube growth was achieved at $600{ }^{\circ} \mathrm{C}$ (Fig. 5b). The structures of small-diameter SWCNTs were further verified by TEM characterizations (Fig. 5c). Like any other SWCNTs grown at low temperatures $[8,19,21,22,31]$, the yield of SWCNTs is not high. However, it is expected that with the optimization of the atomic ratio between Fe and Mn in the catalyst, both the SWCNT yield and purity could be improved, as previous reported CoMo [41] catalyst and FeCu catalyst [42].

The results indicate that the addition of Mn improved the activity of Fe catalysts and gives full play to their synergistic catalytic reaction [40]. At such a low reaction temperature, the presence of Mn facilitates the reduction of iron oxide and thus increases the surface active sites, leading to the formation of small Fe nanoparticle, capable of growing small diameter SWCNTs with a narrow chirality distribution. The crystalline species in FeMn-MgO catalyst

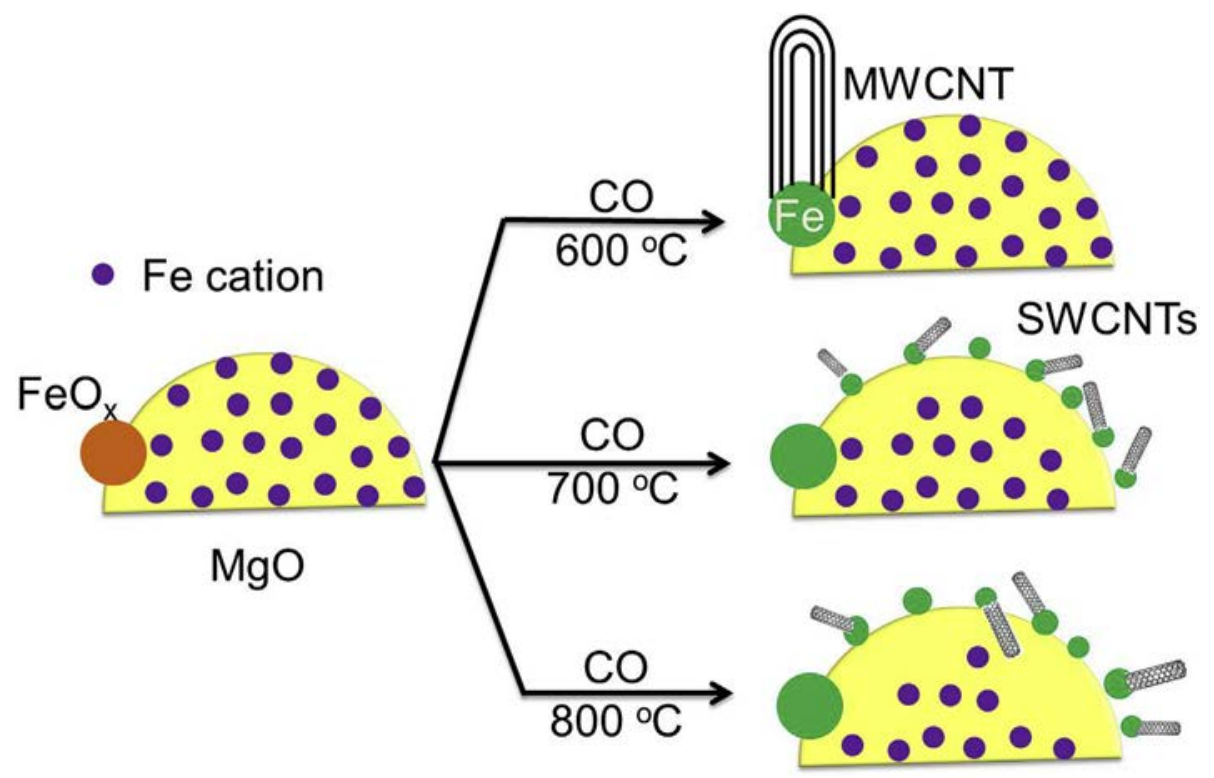

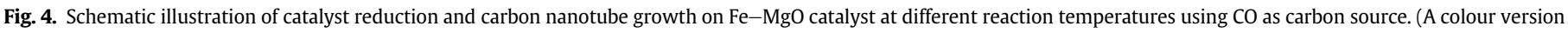
of this figure can be viewed online.) 

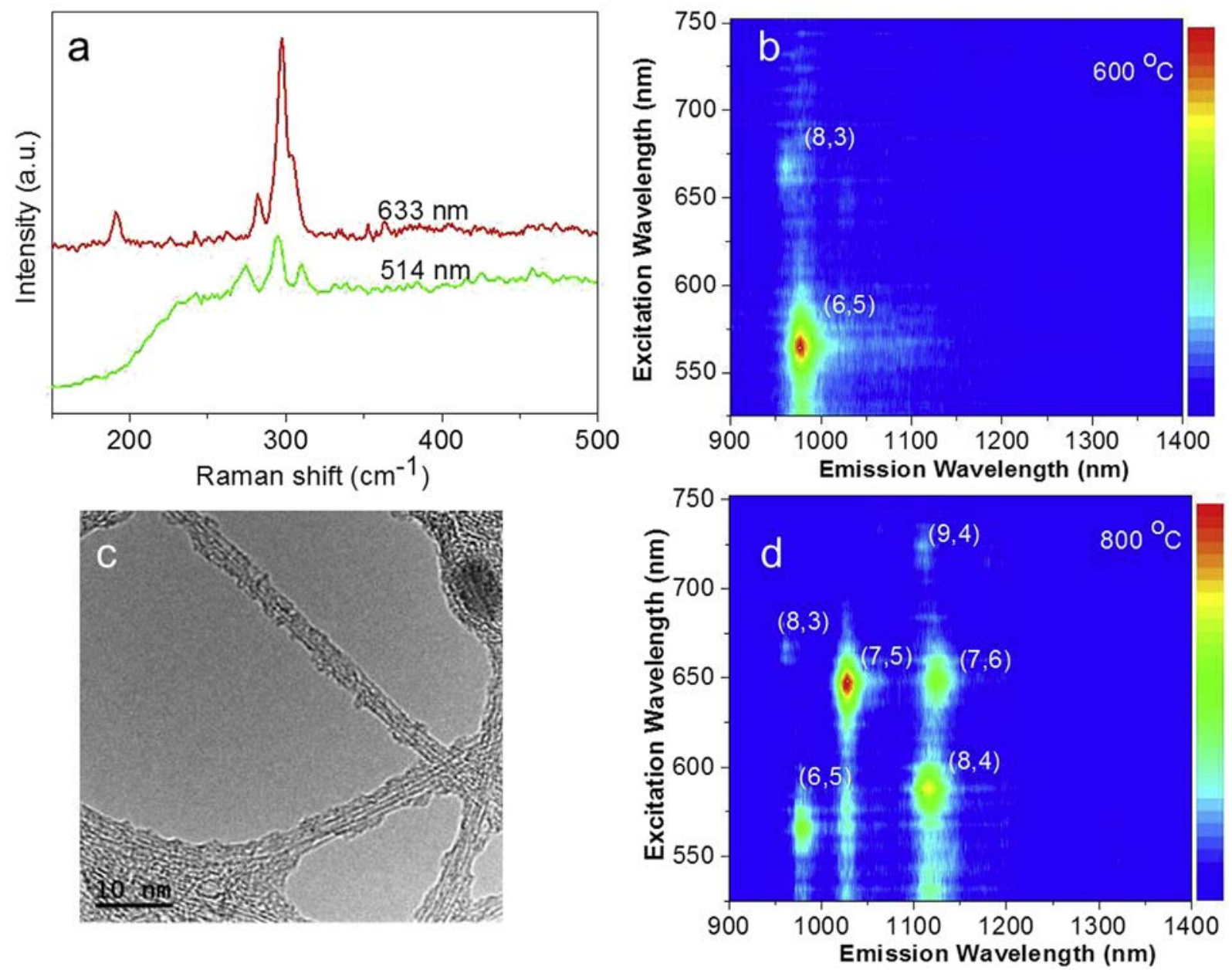

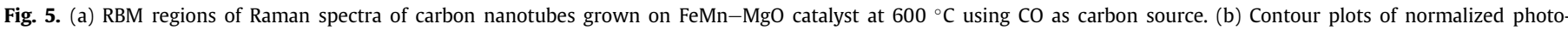

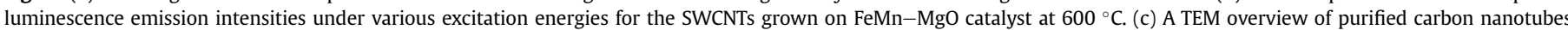

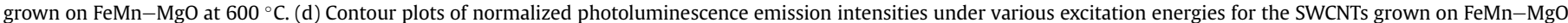
catalyst at $800{ }^{\circ} \mathrm{C}$. (A colour version of this figure can be viewed online.)

is studied by XRD (ESI Fig. S5). ESI Fig. S6 depicts the $\mathrm{H}_{2}$-TPR profile of FeMn-MgO catalyst, showing that the catalyst can be readily reduced below $600{ }^{\circ} \mathrm{C}$. The $\mathrm{H}_{2}$-TPR result well explains the successful growth of SWCNTs at $600{ }^{\circ} \mathrm{C}$. Although Mn can also affect the selectivity towards methane and $\mathrm{C}_{2}-\mathrm{C}_{4}$ olefins during FischerTropsch process [39], its influence on the SWCNT chirality distribution is insignificant. This is because in contrast to Fischer-Tropsch process where $\mathrm{H}_{2}$ is also introduced to produce hydrocarbons, only pure CO is introduced in our CVD process. The negligible effect of Mn on tube chirality is confirmed by comparing the chirality distributions of FeMn-grown and Fe-grown SWCNTs synthesized at identical conditions. As depicted in Fig. 5d, the chirality distribution of FeMn-grown SWCNTs is quite similar to that of SWCNTs grown on monometallic Fe catalyst (Fig. 3d). Meanwhile, the crystalline species and binding energy of $\mathrm{Mn}$ in FeMn-MgO catalyst was studied by XRD (ESI Fig. S6) and XPS (ESI Fig. S7), respectively. Compared with $\mathrm{Mn}-\mathrm{MgO}$ catalyst, no new peak appears in the XRD pattern of FeMn-MgO and no binding energy change of $\mathrm{Mn}$ is observed in the XPS (ESI Fig. S7). From the phase diagram, it seems that Fe and Mn could form alloy. However, the characterizations of reduced catalyst (ESI Fig. S8) and photoluminescence of resulting SWCNTs further suggest there is no alloy formation in the FeM$\mathrm{n}-\mathrm{MgO}$ catalyst.

In short, the major role of $\mathrm{Mn}$ is to facilitate the reduction of Fe cations, leading to the growth of SWCNTs at low temperatures. The chirality distribution of SWCNTs is determined by the active component $(\mathrm{Fe})$ in the catalyst, the high carbon solubility of which facilitates the growth of small-diameter SWCNTs with a

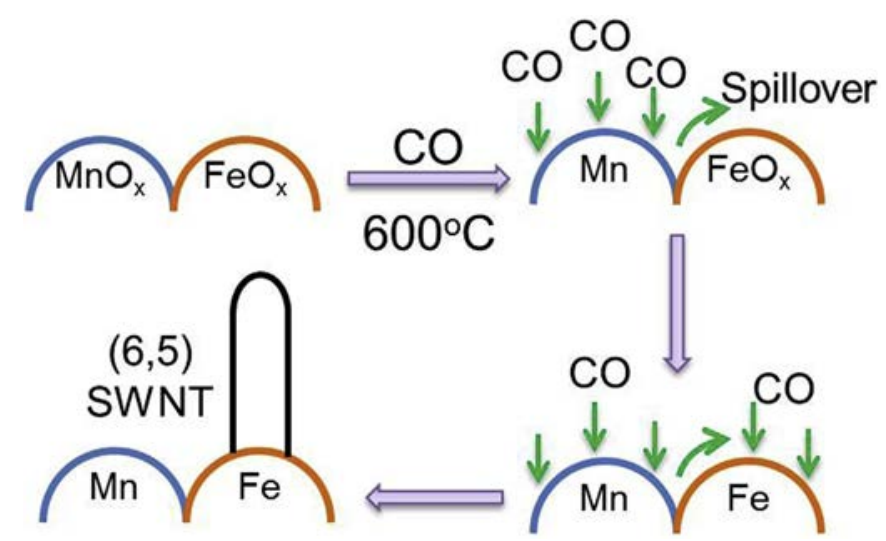

Fig. 6. Schematic illustration of $\mathrm{CO}$ spillover from $\mathrm{Mn}$ to iron oxide, facilitating the reduction of Fe for SWCNT nucleation by a perpendicular mode. (A colour version of this figure can be viewed online.) 
perpendicular mode, accounting for a very narrow chirality distribution of SWCNTs. The catalyst reduction and tube growth processes are schematically illustrated in Fig. 6.

\section{Conclusions}

To conclude, monometallic Fe-MgO and bimetallic FeMn-MgO catalysts were designed for CVD growth of carbon nanotubes. Optical studies showed that using $\mathrm{CO}$ as the carbon source, $\mathrm{Fe}-\mathrm{MgO}$ catalyst favored the growth of SWCNTs with a narrow chirality distribution at a temperature of $700{ }^{\circ} \mathrm{C}$. No SWCNT growth was observed on the $\mathrm{Fe}-\mathrm{MgO}$ catalyst when decreasing the reaction temperature, arising from the difficulties in reducing the Fe cations. The addition of $\mathrm{Mn}$ to $\mathrm{Fe}-\mathrm{MgO}$ catalyst facilitates the reduction of Fe cations, leading to the predominant growth of $(6,5)$ SWCNTs at $600{ }^{\circ} \mathrm{C}$. The narrow chirality distributions of Fe-grown SWCNTs are attributed to the perpendicular nucleation mode, adopted by SWCNTs grown on high-carbon-solubility Fe nanoparticles in CO atmosphere. This work adds new insights into the relationship between SWCNT chirality distribution and carbon solubility of catalyst nanoparticles, sheds more light on the understandings to SWCNT nucleation and growth mechanisms.

\section{Acknowledgements}

The authors would like to acknowledge Scientific Research Foundation of Shandong University of Science and Technology for Recruited Talents (No. 2016RCJJ001), the National High Technology Research and Development Program of China (863 Plan, 2015AA034404), the Natural Science Foundation of China (No. 51272141) and Taishan Scholars Project of Shandong (No. TS20110828). The research leading to these results has received funding from the European Union Seventh Framework Programme (FP7/2007-2013) under grant agreement $\mathrm{n}^{\circ}$ 604472. We thank Dr. D. Shang, Dr Q. Liu, Dr. R. Zhang, Dr. L. Liu and Mr. Z. Li for their experimental help. The project was also supported by RFBR grant 14-02-31829, 13-02-01354, 4-02-00777, 15-32-70005 and made use of the Aalto University Nanomicroscopy Center (Aalto-NMC) premises.

\section{Appendix A. Supplementary data}

Supplementary data related to this article can be found at http:// dx.doi.org/10.1016/j.carbon.2016.07.048.

\section{References}

[1] R.V. Noorden, The trials of new carbon, Nature 469 (2011) 14-16.

[2] T. Yamada, T. Namai, K. Hata, D.N. Futaba, K. Mizuno, J. Fan, et al., Size-selective growth of double-walled carbon nanotube forests from engineered iron catalysts, Nat. Nanotechnol. 1 (2006) 131-136.

[3] H.S. Yang, L. Zhang, X.H. Dong, W.M. Zhu, J. Zhu, B.J. Nelson, et al., Precise control of the number of walls formed during carbon nanotube growth using chemical vapor deposition, Nanotechnol 23 (2012) 065604.

[4] M. He, J. Dong, K. Zhang, F. Ding, H. Jiang, A. Loiseau, et al., Precise determination of the threshold diameter for a single-walled carbon nanotube to collapse, ACS Nano 8 (2014) 9657-9663.

[5] C.L. Cheung, A. Kurtz, H. Park, C.M. Lieber, Diameter-controlled synthesis of carbon nanotubes, J. Phys. Chem. B 106 (2002) 2429-2433.

[6] F. Zhang, P.-X. Hou, C. Liu, B.-W. Wang, H. Jiang, M.-L. Chen, et al., Growth of semiconducting single-wall carbon nanotubes with a narrow band-gap distribution, Nat. Commun. 7 (2016) 11160.

[7] T.P. McNicholas, L. Ding, D. Yuan, J. Liu, Density enhancement of aligned single-walled carbon nanotube thin films on quartz substrates by sulfurassisted synthesis, Nano Lett. 9 (2009) 3646-3650.

[8] S.M. Bachilo, L. Balzano, J.E. Herrera, F. Pompeo, D.E. Resasco, R.B. Weisman, Narrow $(n, m)$-distribution of single-walled carbon nanotubes grown using a solid supported catalyst, J. Am. Chem. Soc. 125 (2003) 11186-11187.

[9] X. Li, X. Tu, S. Zaric, K. Welsher, W.S. Seo, W. Zhao, et al., Selective synthesis combined with chemical separation of single-walled carbon nanotubes for chirality selection, J. Am. Chem. Soc. 129 (2007) 15770-15771.

[10] M. He, A.I. Chernov, P.V. Fedotov, E.D. Obraztsova, J. Sainio, E. Rikkinen, et al., Predominant $(6,5)$ single-walled carbon nanotube growth on a copperpromoted iron catalyst, J. Am. Chem. Soc. 132 (2010) 13994-13996.

[11] M. He, H. Jiang, B. Liu, P.V. Fedotov, A.I. Chernov, E.D. Obraztsova, et al., Chiralselective growth of single-walled carbon nanotubes on lattice-mismatched epitaxial cobalt nanoparticles, Sci. Rep. 3 (2013) 1460.

[12] F. Yang, X. Wang, D. Zhang, J. Yang, D. Luo, Z. Xu, et al., Chirality-specific growth of single-walled carbon nanotubes on solid alloy catalysts, Nature 510 (2014) 522-524.

[13] H. Wang, Y. Yuan, L. Wei, K. Goh, D. Yu, Y. Chen, Catalysts for chirality selective synthesis of single-walled carbon nanotubes, Carbon 81 (2015) 1-19.

[14] M.F.C. Fiawoo, A.M. Bonnot, H. Amara, C. Bichara, J. Thibault-Penisson, A. Loiseau, Evidence of correlation between catalyst particles and the singlewall carbon nanotube diameter: a first step towards chirality control, Phys. Rev. Lett. 108 (2012) 195503.

[15] M. Diarra, A. Zappelli, H. Amara, F. Ducastelle, C. Bichara, Importance of carbon solubility and wetting properties of nickel nanoparticles for single wall nanotube growth, Phys. Rev. Lett. 109 (2012) 185501.

[16] G. Lolli, L. Zhang, L. Balzano, N. Sakulchaicharoen, Y. Tan, D.E. Resasco, Tailoring $(n, m)$ structure of single-walled carbon nanotubes by modifying reaction conditions and the nature of the support of CoMo catalysts, J. Phys. Chem. B 110 (2006) 2108-2115.

[17] B. Wang, C.H.P. Poa, L. Wei, L.-J. Li, Y. Yang, Y. Chen, (n,m) selectivity of singlewalled carbon nanotubes by different carbon precursors on Co-Mo catalysts, J. Am. Chem. Soc. 129 (2007) 9014-9019.

[18] B. Wang, L. Wei, L. Yao, L.J. Li, Y. Yang, Y. Chen, Pressure-induced single-walled carbon nanotube $(\mathrm{n}, \mathrm{m})$ selectivity on Co-Mo catalysts, J. Phys. Chem. C 111 (2007) 14612-14616.

[19] M. He, A.I. Chernov, P.V. Fedotov, E.D. Obraztsova, E. Rikkinen, Z. Zhu, et al. Selective growth of SWNTs on partially reduced monometallic cobalt catalyst, Chem. Commun. 47 (2011) 1219-1221.

[20] C. Zoican Loebick, R. Podila, J. Reppert, J. Chudow, F. Ren, G.L. Haller, et al., Selective synthesis of subnanometer diameter semiconducting single-walled carbon nanotubes, J. Am. Chem. Soc. 132 (2010) 11125-11131.

[21] M. He, A.I. Chernov, E.D. Obraztsova, J. Sainio, E. Rikkinen, H. Jiang, et al., Low temperature growth of SWNTs on a nickel catalyst by thermal chemical vapor deposition, Nano Res. 4 (2011) 334-342.

[22] M. He, H. Jiang, I. Kauppi, P.V. Fedotov, A.I. Chernov, E.D. Obraztsova, et al., Insights into chirality distributions of single-walled carbon nanotubes grown on different CoxMg1-xO solid solutions, J. Mater Chem. A 2 (2014) 5883-5889.

[23] K. Cui, A. Kumamoto, R. Xiang, H. An, B. Wang, T. Inoue, et al., Synthesis of subnanometer-diameter vertically aligned single-walled carbon nanotubes with copper-anchored cobalt catalysts, Nanoscale 8 (2015) 1608-1617.

[24] F. Yang, X. Wang, D. Zhang, K. Qi, J. Yang, Z. Xu, et al., Growing zigzag $(16,0)$ carbon nanotubes with structure-defined catalysts, J. Am. Chem. Soc. 137 (2015) 8688-8691.

[25] Q. Zhao, Z. Xu, Y. Hu, F. Ding, J. Zhang, Chemical vapor deposition synthesis of near-zigzag single-walled carbon nanotubes with stable tube-catalyst interface, Sci. Adv. 2 (2016) e1501729.

[26] H. Ago, S. Imamura, T. Okazaki, T. Saito, M. Yumura, M. Tsuji, CVD growth of single-walled carbon nanotubes with narrow diameter distribution over Fe/ $\mathrm{MgO}$ catalyst and their fluorescence spectroscopy, J. Phys. Chem. B 109 (2005) 10035-10041.

[27] G.Q. Ning, F. Wei, Q. Wen, G.H. Luo, Y. Wang, Y. Jin, Improvement of Fe/MgO catalysts by calcination for the growth of single-and double-walled carbon nanotubes, J. Phys. Chem. B 110 (2006) 1201-1205.

[28] Q.W. Li, H. Yan, Y. Cheng, J. Zhang, Z.F. Liu, A scalable CVD synthesis of highpurity single-walled carbon nanotubes with porous $\mathrm{MgO}$ as support material, J. Mater. Chem. 12 (2002) 1179-1183.

[29] M.H. He, S. Vasala, H. Jiang, M. Karppinen, E.I. Kauppinen, M. Niemela, et al., Growth and surface engineering of vertically-aligned low-wall-number carbon nanotubes, Carbon 50 (2012) 4750-4754.

[30] M. He, H. Jiang, E.I. Kauppinen, J. Lehtonen, Diameter and chiral angle distribution dependencies on the carbon precursors in surface-grown single-walled carbon nanotubes, Nanoscale 4 (2012) 7394-7398.

[31] W.-H. Chiang, R. Mohan Sankaran, Linking catalyst composition to chirality distributions of as-grown single-walled carbon nanotubes by tuning NixFe1-x nanoparticles, Nat. Mater. 8 (2009) 882-886.

[32] O.V. Yazyev, A. Pasquarello, Effect of metal elements in catalytic growth of carbon nanotubes, Phys. Rev. Lett. 100 (2008) 156102.

[33] S. Reich, L. Li, J. Robertson, Control the chirality of carbon nanotubes by epitaxial growth, Chem. Phys. Lett. 421 (2006) 469-472.

[34] A. Moisala, A.G. Nasibulin, E.I. Kauppinen, The role of metal nanoparticles in the catalytic production of single-walled carbon nanotubes-a review, J. Phys. Condens Matter 15 (2003) S3011.

[35] Q. Wang, M.F. Ng, S.W. Yang, Y. Yang, Y. Chen, The mechanism of singlewalled carbon nanotube growth and chirality selection induced by carbon atom and dimer addition, ACS Nano 4 (2010) 939-946.

[36] M. He, B. Liu, A.I. Chernov, E.D. Obraztsova, I. Kauppi, H. Jiang, et al., Growth mechanism of single-walled carbon nanotubes on iron-copper catalyst and chirality studies by electron diffraction, Chem. Mater. 24 (2012) 1796-1801.

[37] E. de Smit, A.M. Beale, S. Nikitenko, B.M. Weckhuysen, Local and long range order in promoted iron-based Fischer-Tropsch catalysts: a combined in situ 
X-ray absorption spectroscopy/wide angle X-ray scattering study, J. Catal. 262 (2009) 244-256.

[38] H. Schulz, Short history and present trends of Fischer-Tropsch synthesis, Appl. Catal. A 186 (1999) 3-12.

[39] K.B. Jensen, F.E. Massoth, Studies on iron-manganese oxide carbon monoxide catalysts, J. Catal. 92 (1985) 98-108.

[40] X. Li, B. Zhong, S. Peng, Q. Wang, Fischer-Tropsch synthesis on Fe-Mn ultrafine catalysts, Catal. Lett. 23 (1994) 245-250.

[41] W.E. Alvarez, B. Kitiyanan, A. Borgna, D.E. Resasco, Synergism of Co and Mo in the catalytic production of single-wall carbon nanotubes by decomposition of CO, Carbon 39 (2001) 547-558.

[42] M. He, A.I. Chernov, E.D. Obraztsova, H. Jiang, E.I. Kauppinen, J. Lehtonen, Synergistic effects in $\mathrm{FeCu}$ bimetallic catalyst for low temperature growth of single-walled carbon nanotubes, Carbon 52 (2013) 590-594. 